\title{
Studies on the Circulation of the Previable Human Fetus
}

\author{
Abraham M. Rudolph ${ }^{[25]}$, Michael A. Heymann, Kari A. W. Teramo, Cynthia T. Barrett, \\ AND Niels C. R. RÄIHÄ \\ Cardiovascular Research Institute and the Department of Pediatrics, University of California, San Francisco, California, USA; \\ and the I and II Departments of Obstetrics and Gynecology, Helsinki University Central Hospital, Helsinki, Finland
}

\begin{abstract}
Extract
The circulation was studied in 33 previable human fetuses (12-272 g) delivered by hysterotomy, while the placenta was still attached. The umbilical vein (UV) and in some instances umbilical or carotid artery (FA) were cannulated. Fetal and maternal $\mathrm{pH}, \mathrm{PO}_{2}$, and $\mathrm{PCO}_{2}$ were measured. Radionuclide-labeled microspheres (50 $\mu$ in diameter) were injected into the UV on one or more occasions from 1 to $36 \mathrm{~min}$ after delivery of the fetus. The distribution of the cardiac output (CO) was calculated from the relative amounts of radioactivity in each organ. In 11 fetuses, FA blood samples were withdrawn during microsphere injection, and $\mathrm{CO}$ and actual organ blood flows were measured.

With advancing gestational age (10-20 weeks) there was an increase in total inferior vena caval return from 64 to $75 \%$ of $\mathrm{CO}$. The proportion of $\mathrm{CO}$ to the placenta increased from 17 to $33 \%$ and to the gut from 5.5 to $9.2 \%$. Superior vena caval return decreased from 32 to $23 \%$, and the percentage of $\mathrm{CO}$ to the kidneys fell from 6.5 to $3.2 \%$. In those fetuses in which repeated observations were made, there was a fairly uniform decrease in proportion of $\mathrm{CO}$ distributed to the placenta, probably owing to umbilical vessel constriction. This deterioration was not reflected by UV blood gases which in fact showed a decrease in $\mathrm{PCO}_{2}$ and rise of $\mathrm{PO}_{2}$, when FA showed a rise of $\mathrm{PCO}_{2}$ and fall in $\mathrm{PO}_{2}$ and $\mathrm{pH}$. Associated with the fall in FA pH there was an increase in the proportion of $\mathrm{CO}$ to the brain, myocardium, and adrenals. The proportion of $\mathrm{CO}$ to the brain increased significantly with increase of $\mathrm{FA} \mathrm{PCO}_{2}$.
\end{abstract}

\section{Speculation}

The circulation of the previable human fetus may be studied at the time of hysterotomy. It is most important to realize that, even though umbilical venous blood gases may appear to reflect good physiological function, umbilical flow may be markedly decreased. This must be taken into account in all attempts to study placental function.

\section{Introduction}

Recently, we described methods for studying the course and distribution of the circulation in fetal lambs by injecting radionuclide-labeled microspheres into peripheral limb veins or the umbilical vein [12, 13]. In considering the possible application of the results in lambs to our understanding of human fetal circulation, it became quite clear that there were sev- 
eral major differences in physique which could alter not only distribution of blood flow but possibly also the course of the circulation. One major concern was that since the head of the human fetus is much larger relative to body size than the head of the lamb, there may be an enormous difference in the proportion of total fetal cardiac output going to the head; this would result in a larger venous return through the superior vena cava with possible alteration in the proportions of superior and inferior vena caval blood crossing the foramen ovale.

Attempts to study the circulation in the primate have been complicated by difficulty in making measurements before the uterus contracts and the placenta is expelled. The course of the circulation in human fetuses has been examined by means of angiography [7, 10]. The fetuses had been removed from the uterus, however, and since the placental circulation, which in the lamb has been shown to receive about $50 \%$ of the total fetal cardiac output, was eliminated, these studies cannot be considered as representative of the fetal circulation.

We have studied the course and distribution of the circulation in the human fetus in the first half of gestation before it is viable. The studies were conducted in the Obstetric Clinics of the Helsinki University Central Hospital, where there has been an extensive experience in performance of legal abortion by means of open hysterotomy. The methods we previously described in lambs to investigate the course of venous return, the measurement of cardiac output and organ blood flows, by injection of radionuclicle-labeled microspheres into peripheral veins, were applied to the human fetus with some modification [12].

We present here our experiences with studies on 33 human fetuses weighing 12-272 $\mathrm{g}$ and with estimated gestational ages of 10-20 weeks.

\section{Materials and Methods}

The women whose fetuses were the subjects of this study were referred for abortion only after careful consideration of the advisability of the procedure by a legally constituted board. The board approved the procedure only in those cases in whom they considered sound medical reasons to exist. None of the investigators served on the board, nor were they in any way responsible for referring women to the board for the abortion procedure. In all cases, legal consent for the procedures was provided either by the woman herself or by a responsible guardian.

None of the women suffered from any acute physical disease or disturbance at the time of the study. One woman had recently received radioactive iodine for treatment of thyroid carcinoma, and another had recovered from acute peritonitis several days before the study.

\section{Anesthesia}

The mothers were premedicated with atropine, mepericline, and promethazine. In preliminary observations, it was noted that the routine anesthesia employed for the abortion procedure was not suitable for the proposed studies. When the operation was performed under sodium pentothal, nitrous oxide, and oxygen anesthesia, after opening the uterus and delivering the fetus, there were rapid uterine contractions, and the placenta separated and was expelled in 3-5 $\min$. In view of previous experiences we have had in animal experiments, which indicated that halothane anesthesia decreased uterine contraction, the anesthesia used in 31 of the 33 studies was as follows. Induction was achieved with sodium pentothal and anesthesia was then maintained with $0.5 \%$ halothane, $50 \%$ nitrous oxide, and $50 \%$ oxygen. In two cases sodium pentothal was used for induction and nitrous oxide $60-70 \%$ and oxygen $30-40 \%$ was given for continuing anesthesia, with additional small amounts of sodium pentothal.

\section{Delivery of the Fetus}

The abdomen was opened through either a midline or transverse suprapubic incision; in 32 of the 33 cases a transverse incision was made in the lower uterine segment. In one instance, the umbilical cord presented at the incision site, and the umbilical vein was catheterized and one set of microspheres injected before delivering the fetus. The fetus was delivered and placed on a hot water bottle positioned under the sterile drapes on the mother's pelvis. Great care was taken to avoid any tension or pressure on the umbilical cord. The fetus was covered with a dry sterile drape to prevent undue cooling by evaporation.

\section{Fetal Catheterization}

The umbilical vein was catheterized in every fetus within $1 \mathrm{~min}$ of delivery. In one fetus, the umbilical vein catheter was inserted before delivery as the cord presented at the uterine incision. The catheter consisted of a 5-6 inch length of soft polyvinyl tubing (id 0.030 inch, od $0.048 \mathrm{inch}$ ) into the end of which was inserted a Teflon tip. This tip was prepared by heating Teflon tubing (id $0.010 \mathrm{inch}$, od $0.030 \mathrm{inch}$ ) in an 
open flame and pulling it to form a capillary tube. A short tapered segment (about 0.5 inch) was selected and tied into the vinyl tubing. The tip was cut at an angle of $\pm 45^{\circ}$. In the smaller fetuses the Teflon catheter could readily be inserted into the umbilical vein by direct puncture, but in older fetuses it was necessary to make a small incision in the Wharton's jelly covering the vein, after which the catheter was easily inserted for a distance of 3-5 mm. There was no distortion of the vein, and obstruction was minimal. No constriction of the vein was noted, except in one fetus, in which mild constriction was noted after the catheter had been in place about $20 \mathrm{~min}$. In 11 fetuses a similar Teflon and vinyl catheter was inserted into one umbilical artery, but since it was noted that contraction occurred within a few minutes of insertion, this procedure was abandoned in subsequent studies.

In the fetuses weighing less than $50 \mathrm{~g}$, no attempt was made to catheterize other fetal vessels. In some of the larger fetuses, using local anesthesia with $1 \%$ mepivacaine hydrochloride a left or right carotid artery and internal jugular vein were exposed, and attempts were made to catheterize these vessels. This was successfully accomplished with the carotid artery in 10 fetuses and with the jugular vein in 9 instances. The catheters used were vinyl (id 0.015 inch, od 0.035 inch or id 0.011 inch, od 0.024 inch); a short length (l inch) was connected to larger vinyl tubing (id 0.030 inch, od 0.062 inch) so as to avoid a great length of fine tubing with a high resistance.

\section{Microsphere Injection}

The microspheres [14] used were $50 \mu$ in diameter as clescribed previously [12] and labeled with the following radionuclides: ${ }^{125} \mathrm{I},{ }^{141} \mathrm{Ce},{ }^{51} \mathrm{Cr},{ }^{85} \mathrm{Sr}$, and ${ }^{95} \mathrm{Nb}$. They were suspended in a $20 \%$ dextran solution, to which a small amount of polyoxyethylene (80) sorbi$\tan$ monooleate (Tween) [15] was added. The solution with the spheres was sterilized in rubber-capped injection vials. The spheres in solution were injected into sterile mixing chambers, similar to those described previously; the chamber was then filled with sterile normal saline. The outlet was connected to the umbilical venous catheter immediately after its insertion, and one set of micropheres was injected over a 20 - to 30 -sec period. In the first six studies, $2-3 \mathrm{ml}$ normal saline were used for the injection, but subsequently, to avoid hemodilution, maternal venous blood was injected through the chamber. One or two injections of spheres with different radionuclide labels were made in succession into the umbilical vein. The dissection of the jugular vein and carotid artery was then carried out and additional microsphere injections were then made into the umbilical vein and jugular vein, while blood samples were continuously withdrawn from the carotid or umbilical artery at steady rates of $1.0-3.0 \mathrm{ml} / \mathrm{min}$. The injection of blood into the mixing chambers was continued at a rate which replaced the blood withdrawn from the carotid artery. A single microsphere injection in 16, two injections in 9, and three injections in 8 fetuses were made. A total of 58 injections were made in the 33 fetuses up to 36 min after delivery and 12,000-25,000 spheres were used for each injection.

\section{Arterial Pressure Measurement}

In 8 of the 10 fetuses in which a carotid artery catheter was inserted, pressures were measured using a sterile pressure transducer [16]. The tracing was displayed on a direct-writing oscillograph [16].

\section{Blood Sampling for $p H$ and Blood Gases}

Fetal blood samples $(0.6 \mathrm{ml})$ for $\mathrm{pH}$ and blood gases were obtained repeatedly from the umbilical vein and umbilical or carotid artery. In 25 of the women, capillary blood was obtained from the earlobe for analysis for $\mathrm{pH}, \mathrm{PCO}_{2}$, and $\mathrm{PO}_{2}$. These samples were collected simultaneous with, or within a few minutes of collection of samples from the fetus. In three instances a nylon cannula was inserted percutaneously into a maternal brachial or radial artery. Blood gas and $\mathrm{pH}$ measurements were made on a $\mathrm{pH}$ meter [17] with appropriate electrodes.

\section{Check for Absence of Transport of Nuclide into Mother}

Extensive experience in sheep had demonstrated that radionuclide-labeled microspheres injected into the fetal circulation did not cross the placental barrier into the maternal circulation, as evidenced by an absence of any radioactivity in the maternal lung. We felt it was important to examine the possibility of transfer of microspheres in a primate before proceeding with the human fetal studies. Labeled microspheres were injected into five fetal rhesus monkeys at varying periods of gestation and maternal lungs and liver were examined. The absence of radioactivity in these organs or in the maternal uterus or decidua after removal of the fetus and placenta indicated that the microspheres were trapped in the placenta and did not enter maternal tissues. 
In two early studies, a needle was inserted into the right uterine vein and a blood sample was withdrawn continuously while micropheres were injected into the fetal umbilical vein. Absence of radioactivity was checked. In all women, after the fetus and placenta had been removed, the decidual scrapings from the whole uterine surface were collected, and absence of radioactivity was determined.

\section{Dissection of Fetus and Measurement of Radioactivity}

The umbilical cord was divided into two segments. The one-quarter to one-half segment of the cord closest to the fetus was always used for cannulation of the vein, and we wished to ascertain whether any of the injected nuclide was sequestered at the injection site. No evidence of extravasation was found in any of the studies. The fetus and placenta were weighed. In all instances a careful dissection was made to exclude any anatomic defects. The heart and great vessels were carefully scrutinized, and in one instance a very small high ventricular septal defect was noted. Two other fetuses had a bilateral harelip and cleft palate. No other anomalies were noted.

The organs were then dissected, weighed, and placed in plastic counting vials. In all those instances in which a jugular vein and carotid artery were cannulated, the radioactivity in the left and right sides of the brain and skull was measured separately. There were slight differences between the two sides, but there was no correlation with injection site. The portion remaining after all the internal organs had been removed will be referred to as the fetal body. The "upper body" represents all those areas which drain into the superior vena cava excluding the brain, and includes the head, neck, arms, shoulder girdles, and the sternum and chest wall to the second intercostal space. The "lower body" refers to the remainder.

The tissues were all dehydrated in an oven at $75^{\circ}$. The amount of radioactivity for each radionuclide injected was determined, using the precautions and procedures previously described [12]. A l-inch diameter well-scintillation detector with a thallium-activated sodium iodide crystal [18] was used, and the energy spectrum was displayed on a multiple channel pulse height analyzer [19], using only 100 channels. The output was recorded on a paper punch tape [20]. The tape was then processed through a tape editor [21] and desk calculator [22] to provide actual counts for each radionuclide in each organ. The total amount of each radionuclide injected could be determined by adding the counts in individual organs and tissues and thus a percentage distribution could be calculated.

\section{Calculation of Cardiac Output, Distribution, and Organ Flow}

The principles used in these calculations are similar to those previously described in the fetal lamb [12, 13]. Although we could determine actual cardiac output only in those 13 fetuses in which arterial samples were obtained during the radionuclide injections, we were able to calculate the proportionate distribution of the cardiac output in all 33 fetuses. The details used for these calculations are shown in the Appendix.

In the 3 fetuses in which the umbilical artery was sampled the calculations were made as described previously [12]. Placental flow was not measured, but the umbilical arterial sample was used as a reference for determination of actual flows [4, 9]. In the 10 fetuses in which carotid arterial blood was withdrawn, actual blood flow to each portion of the upper body was estimated from the ratio of the amount of radionuclide in each individual organ compared with the amount in the blood sample. The assumption was made that the microspheres were evenly mixed in the blood ejected from the left ventricle and distributed to coronary, carotid, and subclavian arteries (Appendix).

\section{Analysis}

For the purpose of examining possible variations with gestational development, we calculated mean and standard errors for each of four weight groups. These were under $50,51-100,101-150$, and over $150 \mathrm{~g}$. If there appeared to be any systematic differences between the four groups, a linear regression for all points was performed and tested for significance. This analysis was made for the first observation made in each fetus.

In those instances in which the relation of distribution of cardiac output to blood gas status was examined, all observations were included and linear regressions were performed and tested for significance.

\section{Results}

The studies on the human fetus did not cause any ill effects on the mother or prolong hospitalization. The operative procedure was extended for short periods with a maximum of $36 \mathrm{~min}$ (Table I).

\section{Radioactivity in Uterine Venous Blood and Decidua}

There were no counts above background levels in either of the two uterine venous samples collected dur- 
Table I. Distribution of cardiac output immediately after delivery

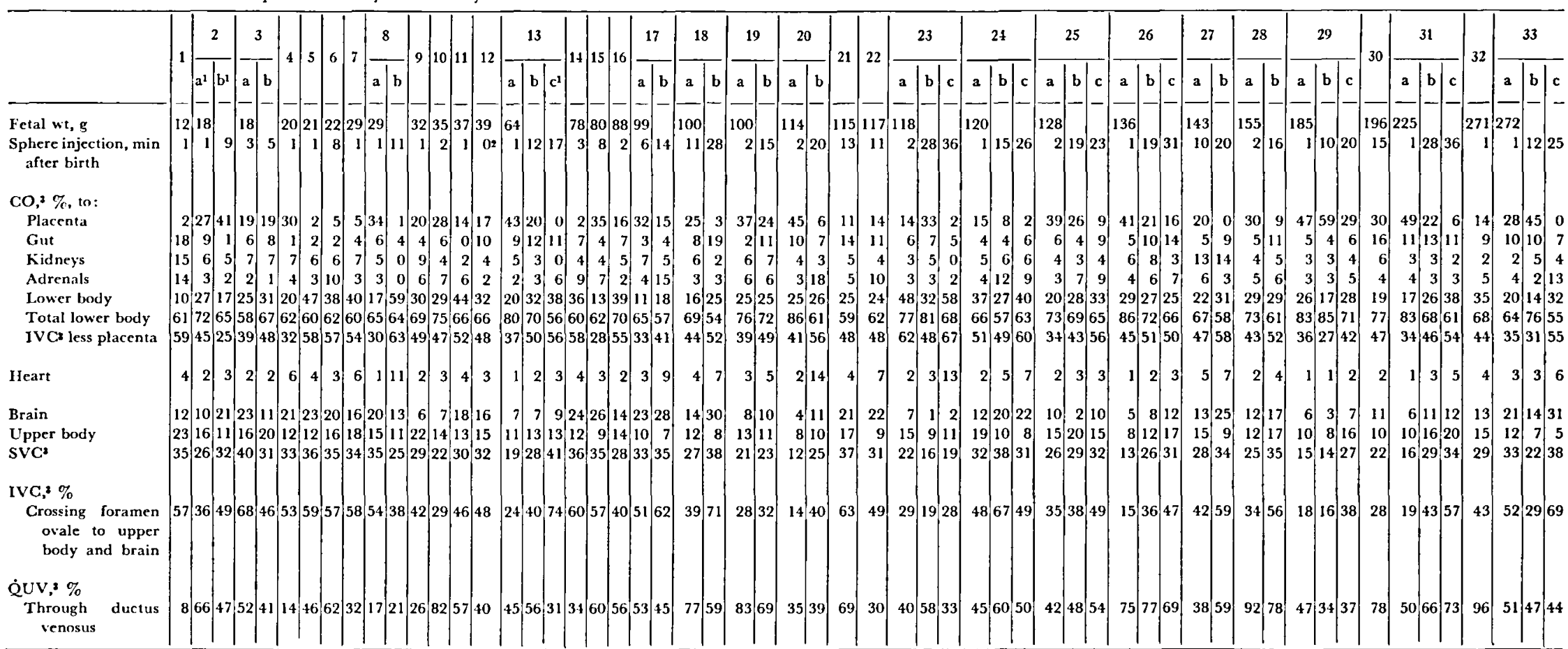

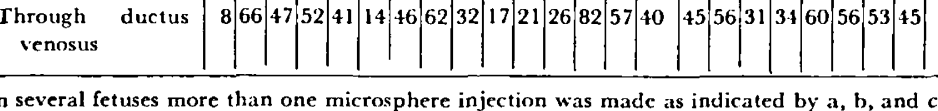

In several fetuses more than one microsphere injection was madc as indicated by $a, b$, and $c$.
In this fetus the microsphere injection was made into the umbilical vein before the fetus was delivered.

? CO: cardiac output; IVC: inferior vena cava; SVC: superior vena cava; $Q U V$ : placental blood flow. 


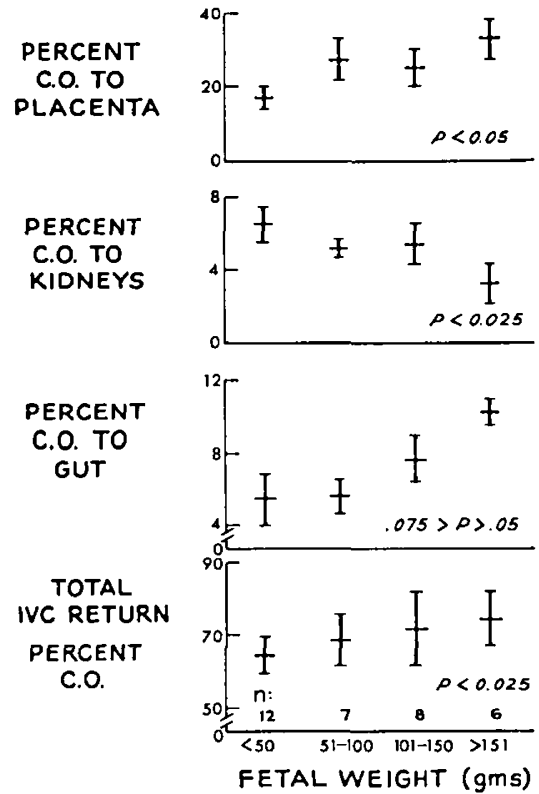

Fig. 1. Differences in percentage of systemic venous return (CO) distributed to the placenta, kidneys, and gut and in the proportion of $\mathrm{CO}$ contributed to by total inferior vena caval (IVC) return in various fetal weight groups (mean $\pm \mathrm{SE}$ ). Values represent the first obscrvations made in each of 33 fetuses. $P$ values refer to linear regression calculated for observations in all 33 fetuses.

ing injection of microspheres into the umbilical vein, nor in the decidual scraping collected in all women studied, indicating that neither microspheres nor free radionuclide entered the maternal side of the circulation.

\section{Distribution of Cardiac Output Immediately after De- livery}

The results in this section are based on the first injection into the umbilical vein, before there had been any disturbance of the fetus to insert peripheral vascular catheters (Table I). In 25 fetuses, this injection was made within 3 min of delivery of the fetus, and in the remaining 8 , from 6 to $15 \mathrm{~min}$ after delivery. We have pooled this material since there was no statistical difference $(P<0.8)$ between these groups. The delayed injections were all made in fetuses weighing over $100 \mathrm{~g}$.

The proportions of the cardiac output (expressed as a percentage of combined superior and inferior vena caval and coronary sinus return) distributed to various fetal organs are shown in Figures 1, 2, and 3. Figure 1 shows the percentages of cardiac output supplying the fetal placenta, kidneys, and gut in the various fetal weight groups. It is evident that there was a relatively small amount of the cardiac output (mean 17\%) received by the placenta in the fetuses weighing less than $50 \mathrm{~g}$, but this increased significantly to a mean of $33 \%$ in fetuses over $150 \mathrm{~g}$. There was a significant decrease in the relative flow to the kidneys, but a progressive increase in flow to the intestines. A progressive increase in the contribution of inferior vena caval return

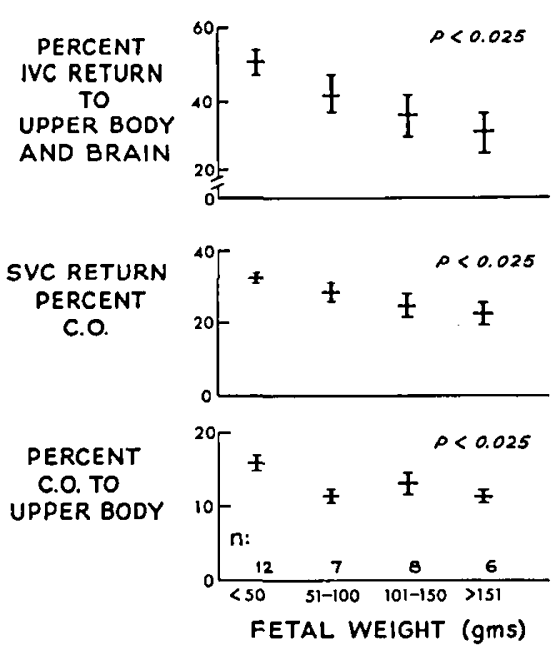

Fig. 2. Differences in proportions of inferior vena caval (IVC) blood which crossed the foramen ovale to be distributed to the upper body and brain, in the percentage of systemic venous return (CO) contributed to by superior vena caval (SVC) return, and in the percentage of CO distributed to the upper body in various fetal weight groups (mean $\pm \mathrm{sE}$ ). Values represent the first observations made in each of 33 fetuses. $P$ values refer to linear regression calculated for observations in all 33 fetuses.
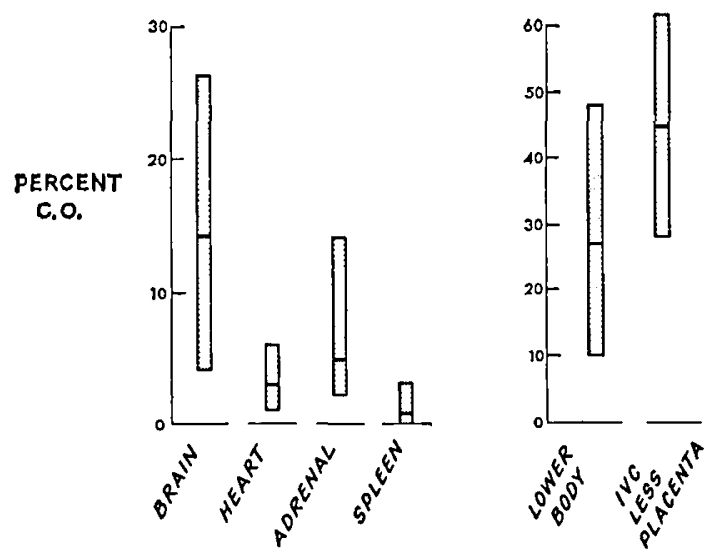

Fig. 3. Proportion of systemic venous return (CO) distributed to the brain, heart, adrenals, spleen, and lower body and percentage of CO contributed by the inferior vena caval (IVC) return cxcluding placental flow (mean and ranges). Values represent the first observations made in each of 33 fetuses. 

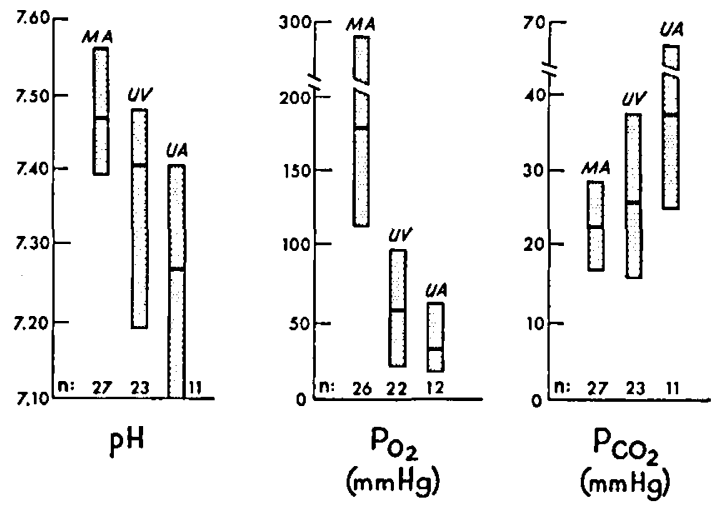

Fig. 4. Maternal capillary (MA), fetal umbilical venous (UV), and fetal umbilical arterial (UA) $\mathrm{pH}, \mathrm{PO}_{2}$, and $\mathrm{PCO}_{2}$ (mean and ranges). Values represent the first observations made in each study and were obtained within $16 \mathrm{~min}$ of delivery in all.

(including umbilical venous flow) to the total cardiac output was noted to occur.

The proportion of inferior vena caval return which crossed the foramen ovale and which was then distributed to the upper body and brain decreased progressively as fetal weight increased (Fig. 2). There was also a significant decrease in the proportion of superior vena caval return which was contributed to total cardiac output, as well as in the proportion of cardiac output distributed to the upper body.

Since there were no statistically significant changes with growth in the percentage of cardiac output distributed to the brain, heart, adrenals, and spleen, nor in the proportions of cardiac output to the lower body or to the lower body including abdominal viscera but excluding placenta, the first observations for all 33 fetuses were pooled and mean and range values are shown in Figure 3. This indicated that the increase in inferior vena caval return was specifically related to an increase in umbilical flow. There was a wide variation in brain flow, but an average of $14.0 \%$ of cardiac output was received by the brain, $2.6 \%$ by the myocardium, and $5.0 \%$ by the adrenals.

Because only a limited number of injections were made into the jugular vein, it was not possible to estimate the proportion of cardiac output distributed to the lung. However, we determined the proportion of inferior venal caval return which passed to the lung; this showed a very wide range, with a mean value of $15.5 \%$.

\section{Blood Gases}

Maternal blood samples showed a high $\mathrm{pH}$ (mean 7.47), a low $\mathrm{PCO}_{2}$ (mean $23 \mathrm{~mm} \mathrm{Hg}$ ), and a high $\mathrm{PO}_{2}$ (mean $180 \mathrm{~mm} \mathrm{Hg}$ ) (Fig. 4). There was considerable variability, probably related to differences in anesthesia, degree of ventilation, and concentration of inspired oxygen. The first umbilical venous and umbilical or carotid arterial samples obtained were also quite variable.

Umbilical venous $\mathrm{pH}$ was, on the average, only slightly lower than maternal arterial levels, and $\mathrm{PCO}_{2}$ was slightly higher. Umbilical arterial $\mathrm{pH}$ was somewhat reduced to an average of $7.27 ; \mathrm{PCO}_{2}$ was considerably higher (mean $38 \mathrm{~mm} \mathrm{Hg}$ ) than in the umbilical veins, and mean arterial $\mathrm{PO}_{2}$ was $34 \mathrm{~mm} \mathrm{Hg}$.

\section{Umbilical-Placental Flow}

In the fetuses in which multiple injections of spheres were made the proportion of the fetal cardiac output distributed to the placenta fell progressively after delivery (Fig. 5). In three instances, however, there was a temporary increase in flow, but in two of these in which a third observation was made, there was a subsequent fall in flow. Complete data of maternal arterial, umbilical venous, and fetal arterial blood gases could not be obtained in all instances in relation to repeated microsphere injections, but an interesting change in fetal blood gases was noted in association with changes in the placental flow. Figure 6 illustrates the relations between maternal and fetal blood gases in two studies in which complete data were obtained. In the fetus on the left, a progressive decrease in the percentage of cardiac output received by the placenta was associated with an increase in umbilical venous $\mathrm{PO}_{2}$ and an approximation of maternal arterial and umbilical venous $\mathrm{PO}_{2}, \mathrm{PCO}_{2}$, and $\mathrm{pH}$. Fetal arterial

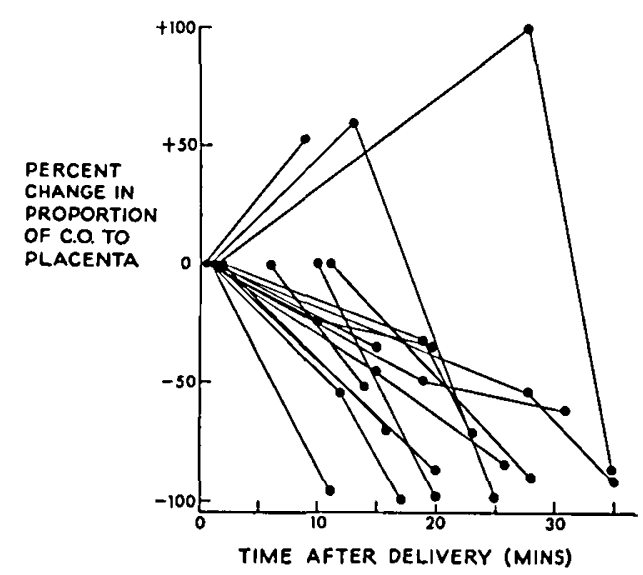

Fig. 5. Percentage change from first observation of the proportion of systemic venous return (CO) distributed to the placenta with passage of time after delivery in 16 fetuses. 


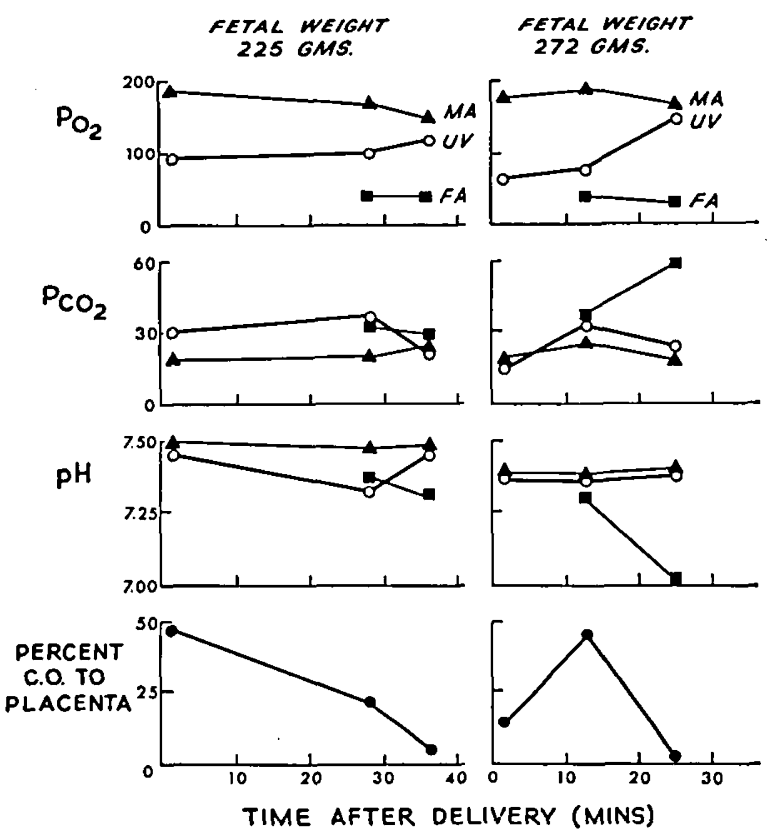

Fig. 6. Changes in maternal capillary (MA), fetal umbilical venous (UV), and fetal carotid arterial (FA) $\mathrm{PO}_{2}, \mathrm{PCO}_{2}$, and $\mathrm{pH}$ and percentage of systemic venous return (CO) distributed to placenta with passage of time after delivery in two fetuses.

$\mathrm{PO}_{2}$ and $\mathrm{pH}$ fell, however. In the fetus shown on the right, there was first a rise and then a fall in the proportion of the cardiac output delivered to the placenta. Umbilical venous $\mathrm{PO}_{2}$, which was first considerably lower than that in maternal artery, rose toward maternal level when placental flow fell. Umbilical venous $\mathrm{PCO}_{2}$ and $\mathrm{pH}$ closely followed maternal levels, but as placental flow fell there was a marked rise in fetal arterial $\mathrm{PCO}_{2}$ and fall in $\mathrm{pH}$.

\section{Relation between Distribution of Cardiac Output and Fetal Blood Gases}

Statistical evaluations of the relation between the percentage of cardiac output delivered to each organ and the fetal arterial and umbilical venous $\mathrm{pH}, \mathrm{PCO}_{2}$ and $\mathrm{PO}_{2}$, respectively, were conducted. No definitive relations between organ distributions and umbilical venous blood gases were demonstrable. A lowering of fetal arterial $\mathrm{pH}$ was associated with a decrease in the percentage of cardiac output delivered to the placenta, a decrease in the total interior vena caval contribution to the cardiac output, and a significant increase in the contribution of superior vena caval return to the total cardiac output (Fig. $7 a, b, c$ ). A decrease of fetal arterial $\mathrm{pH}$ was also associated with a significant increase in the proportion of cardiac output distributed to the adrenals, the myocardium, and the brain (Fig. $8 a, b, c$ ). There was also an increase in the cerebral flow in association with an increase in fetal arterial $\mathrm{PCO}_{2}$ (Fig. 9).

\section{Relation between Proportion of Cardiac Output Dis- tributed to Placenta and Organ Flows}

The proportion of inferior vena caval blood which traversed the foramen ovale and was then distributed
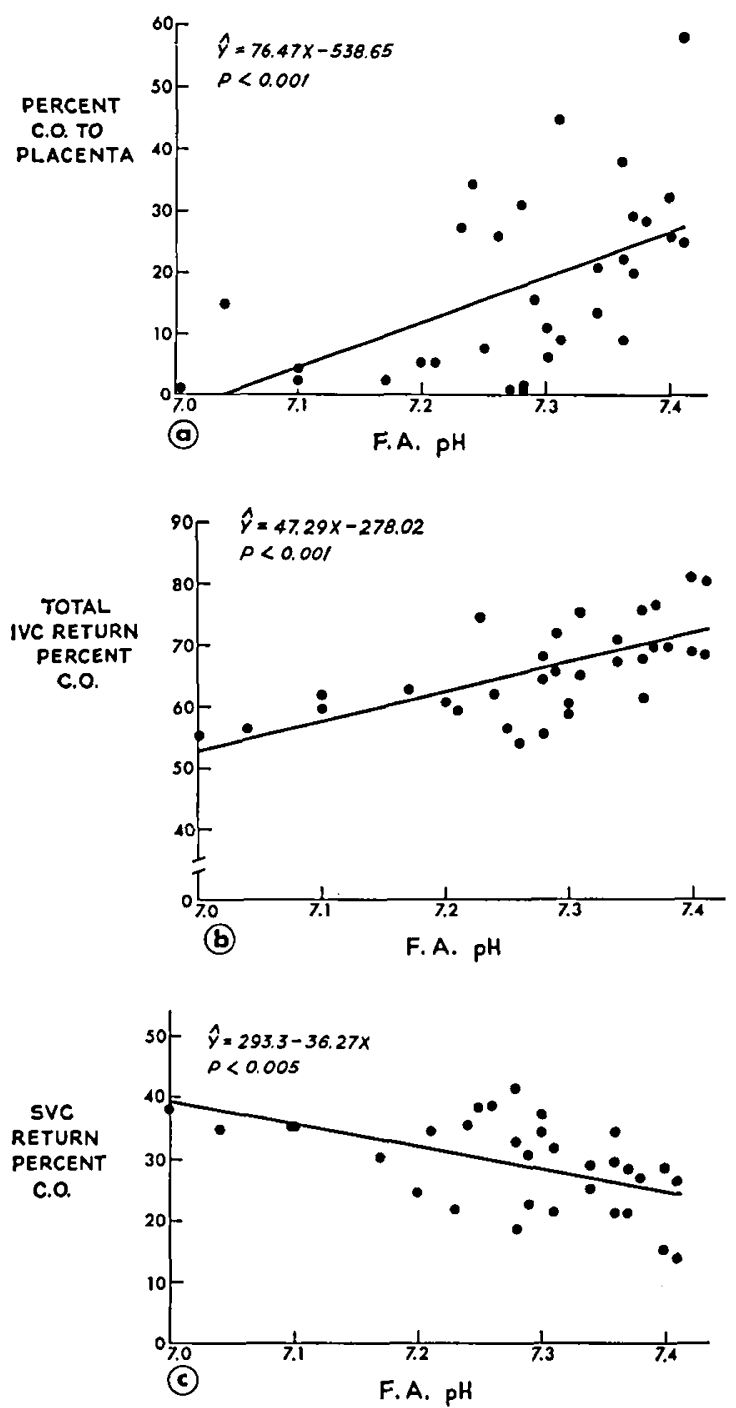

Fig. 7. a: Increase in the percentage of systemic venous return (CO) distributed to the placenta with increase in fetal arterial (FA) pH. (32 observations.) b: Increase in the percentage of systemic venous return (CO) contributed to by total inferior vena caval (IVC) return with increases in fetal arterial (FA) pH. (32 observations.) $c$ : Fall in the percentage of systemic venous return (CO) contributed to by superior vena caval (SVC) return with increases in fetal arterial (FA) pH. (32 observations.) 

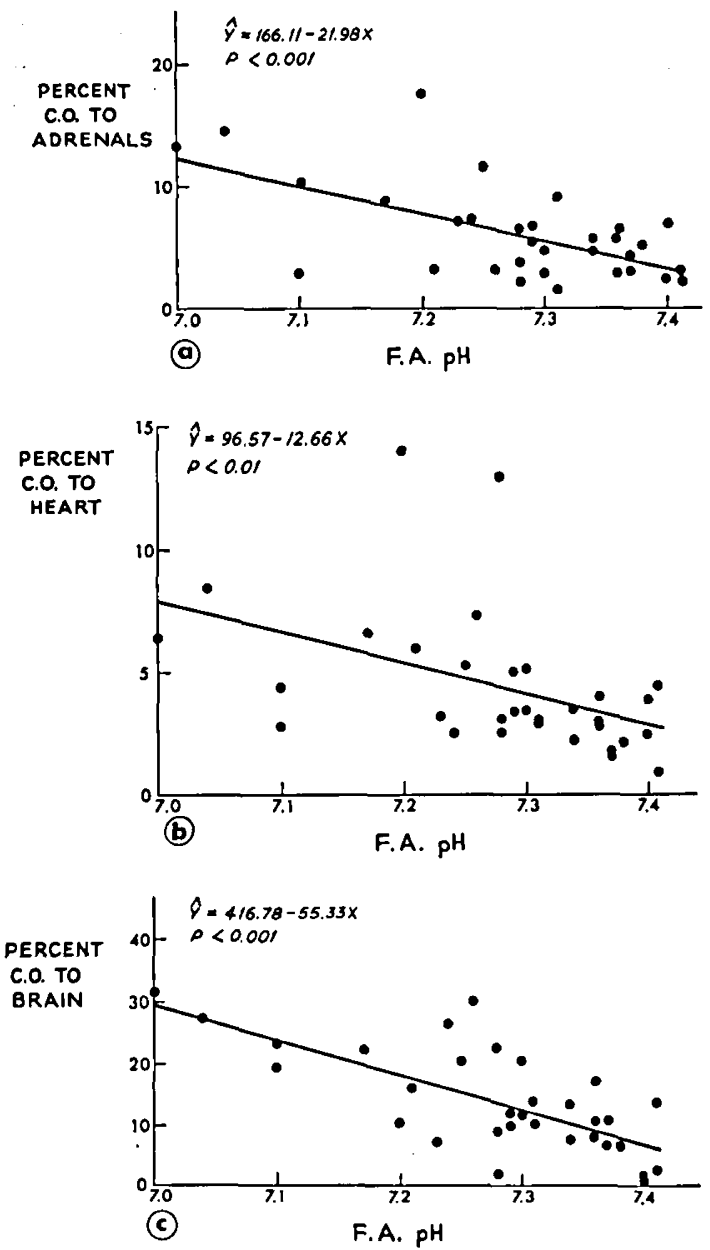

Fig. S. a: Fall in the percentage of systemic venous return (CO) distributed to the adrenals with increase in fetal arterial (FA) pH. (32 observations.) $b$ : Fall in the percentage of systemic venous return (CO) distributed to the heart with increase in fetal arterial (FA) pH. (32 observation.) $c$ : Fall in the percentage of systemic venous return (CO) distributed to the brain with increase in fetal arterial (FA) pH. (32 observations.)

to the upper body and brain increased markedly as the percentage of cardiac output to the placenta decreased (Fig. 10). In the 17 fetuses in which more than one measurement of distribution of blood flow was made, we compared the change in distribution to various organs with the changes in placental distribution. A decrease in the proportion of cardiac output to the placenta was associated with a significant (Wilcoxon signed rank test) increase in the proportion of cardiac output to the brain and heart (Fig. $11 a, b$ ).

\section{Ductus Venosus Flow}

The proportion of umbilical venous return bypassing the liver and directly entering the inferior vena cava across the ductus venosus ranged from 8 to $92 \%$ in different fetuses; this was unrelated to weight. The values for repeated measurements in the same fetus, however, were quite constant despite marked changes in the distribution of cardiac output and the actual umbilical flow, as shown in Figure 12.

\section{Cardiac Output and Organ Blood Flows}

Adequate data for calculation of actual cardiac output and organ flows were obtained in only 11 fetuses weighing $64-225 \mathrm{~g}$. In view of the small number of observations and the wide variation, we have presented mean values and the range of measurements in Table II.

\section{Arterial Pressure}

Reliable tracings for interpretation of carotid arterial pressure and heart rate were obtained in five fetuses. The results are presented in Table III and a representative tracing is shown in Figure 13.

\section{Discussion}

Previous observations on the course of the circulation in the human fetus were made by angiography, only

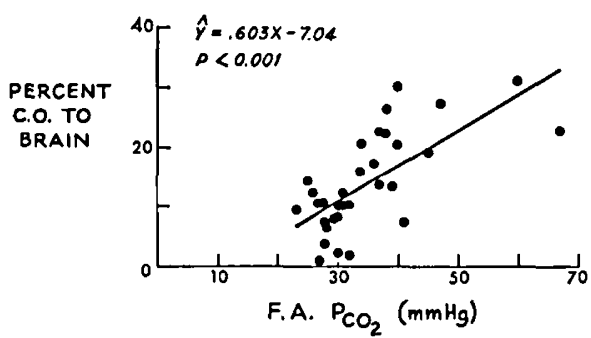

Fig. 9. Increase in the percentage of systemic venous return (CO) distributed to the brain with increase in fetal arterial (FA) $\mathrm{PCO}_{2}$. (32 observations.)

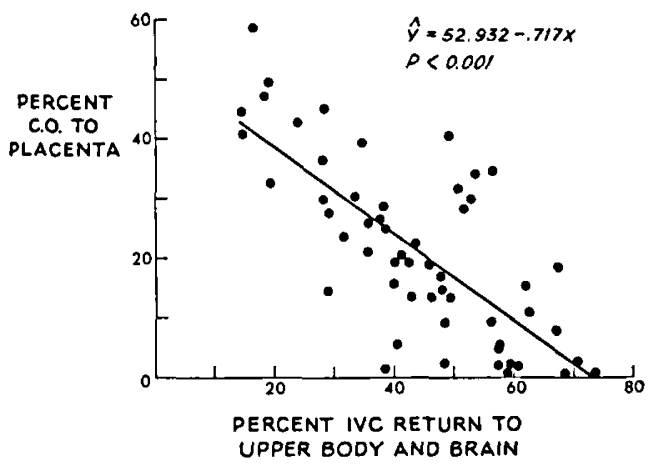

Fig. 10. Increase in the percentage of total inferior vena caval (IVC) return crossing the foramen ovale to be distributed to the upper body and brain with decrease in the percentage of systemic venous return $(\mathrm{CO})$ distributed to the placenta. (54 observations.) 


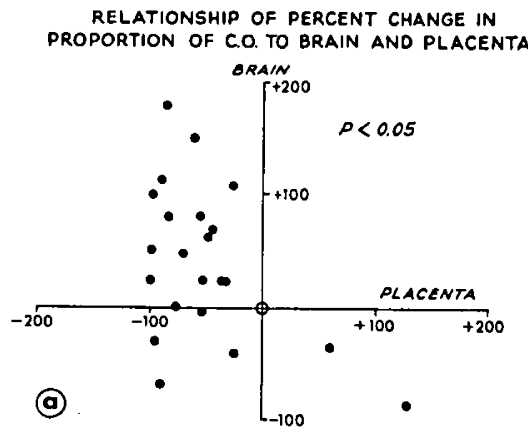

RELATIONSHIP OF PERCENT CHANGE IN PROPORTION OF C.O. TO HEART AND PLACENTA

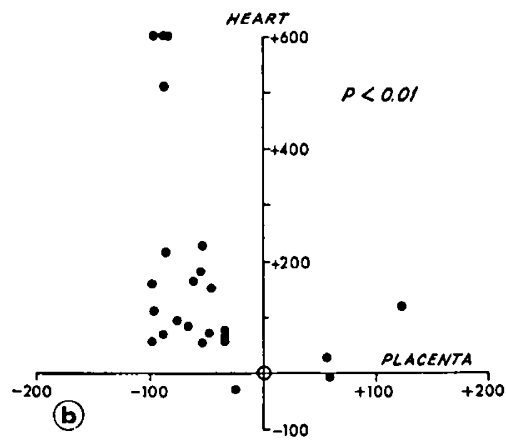

Fig. 11. a: Percentage differences between consccutive observations in the same fetus of the proportions of systemic venous return (CO) distributed to the brain and to the placenta. (22 observations.) $b$ : Percentage differences between consecutive observations in the same fetus of the proportions of systemic venous return (CO) distributed to the heart and to the placenta. (24 observations.)

after the placental circulation had been eliminated [7, 10]. The studies reported are the first attempts to examine the human fetal circulation while the placenta was still attached. The data presented show considerable variability in distribution of cardiac output to various organs. This is partly related to the fact that we elected to inject a relatively small number of spheres, since we wished to avoid interference with the circulation as far as possible in the small fetuses studied. The findings also obviously do not represent the course and distribution of the circulation under normal physiological conditions. The mother and fetus were under influence of anesthesia, which was not systematically controlled, so that maternal blood gases varied considerably. The fetus was delivered by hysterotomy and it is difficult to assess how much this interfered with umbilical-placental circulation. We have shown that in the sheep there is a gradual drop of umbilical blood flow after exteriorization of the fetus, occurring over several hours [5]. It appears that there is a much more rapid and dramatic change in the

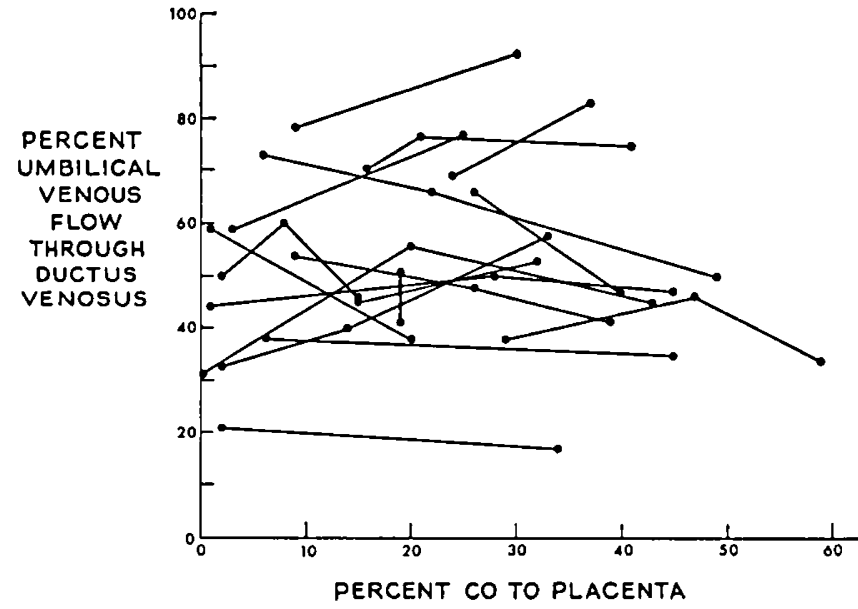

Fig. 12. Relation between the percentage of umbilical venous return passing through the ductus venosus and the magnitude of placental blood flow (expressed as a percentage of systemic venous return (CO) distributed to the placenta) in 17 fetuses.

Table II. Cardiac output and organ blood flows ${ }^{1}$

\begin{tabular}{lcc}
\hline & Mean & Range \\
\hline $\begin{array}{l}\text { Cardiac output, } \mathrm{ml} / \mathrm{kg} \text { fetal } \\
\quad \text { wt/min }\end{array}$ & 363 & $175-660$ \\
Organ flows, $\mathrm{ml} / 100 \mathrm{~g} / \mathrm{min}$ & & \\
Placenta & 11 & $2-49$ \\
Gastrointestinal tract & 101 & $18-235$ \\
Kidneys & 155 & $56-249$ \\
Adrenals & 340 & $105-595$ \\
Lower body & 31 & $10-52$ \\
Heart & 165 & $61-366$ \\
Brain & 25 & $2-48$ \\
Upper body & 12 & $7-19$ \\
\hline
\end{tabular}

1 Eleven human fetuses, weighing $64-225 \mathrm{~g}$.

Table III. Carotid arterial blood pressures and fetal heart rate

\begin{tabular}{cccc}
\hline W't, g & $\begin{array}{c}\text { Systolic/diastolic } \\
\text { pressure, mm IIg }\end{array}$ & $\begin{array}{c}\text { Mean pressure, } \\
\text { mm IIg }\end{array}$ & $\begin{array}{c}\text { Heart } \\
\text { rate/min }\end{array}$ \\
\hline 104 & $33 / 22$ & 28 & 126 \\
118 & $37 / 26$ & 28 & 140 \\
120 & $30 / 27$ & 28 & 120 \\
185 & $46 / 27$ & 35 & 140 \\
225 & $43 / 27$ & 34 & 130 \\
\hline
\end{tabular}

${ }^{1}$ Five human fetuses were studied.

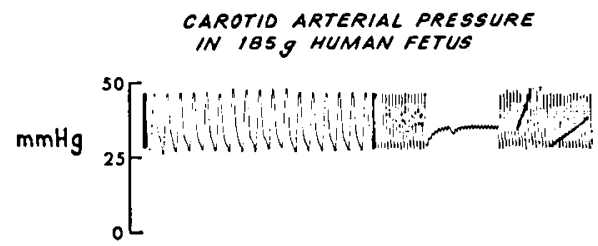

Fig. 13. Carotid arterial pressure in a 185.g human fetus. Heart rate, $140 / \mathrm{min}$. 
human studies. Our preliminary observations on several women who were anesthetized with sodium pentothal alone suggested that there was rapid contraction of the uterus with expulsion of the placenta within a few minutes after the fetus was delivered. This rapid effect was avoided by use of halothane, but we are not sure how long this effect persists after delivering the fetus. In those fetuses in which two or three injections of microspheres were made into the umbilical vein, it was evident that the proportion of the total cardiac output distributed to the placenta decreased rapidly and reached near zero levels within about $30 \mathrm{~min}$ after fetal delivery. Actual blood flows and cardiac output were measured in only a few instances, but it was quite evident that there was an actual reduction in umbilical-placental blood flow, and that the decreased percentage of the cardiac output distributed to the placenta was not a smaller percentage of a markedly increased cardiac output.

The reduction of placental flow did not appear to be related to placental separation alone, since in most instances the placenta was still firmly attached at the end of the study period and had to be manually separated. The probable explanation was the development of umbilical vessel constriction, since the cord vessels were large and well filled immediately after delivery but became progressively paler and narrower. The actual cause of the constriction was not obvious. It could have been due to exposure of the vessels to a lower temperature, to a higher oxygen environment, or to the initial slight handling to insert the umbilical venous cannula.

Recently there has been a trend to study rates of transport of various metabolic substances across the human uteroplacental unit in the fetus delivered at hysterotomy. It is most important to recognize that, since rates of transport are dependent on umbilical blood flow, results will be difficult to interpret without a knowledge of the adequacy of flow. The technique we describe here, employing injection of microspheres into the umbilical vein, provides a relatively easy method of assessing the adequacy of umbilical blood flow.

The effect of the reduction of umbilical flow on $\mathrm{pH}$ and blood gases in the umbilical vessels was of interest and reaffirms the pitfalls in the use of umbilical venous blood gases to assess physiological status of the fetus [5]. As umbilical blood flow fell, umbilical venous $\mathrm{PCO}_{2}$ tended to fall, and umbilical venous $\mathrm{PO}_{2}$ rose toward maternal arterial levels. Fetal arterial blood, however, showed a drop in $\mathrm{PO}_{2}$ and $\mathrm{pH}$, and a rise in $\mathrm{PCO}_{2}$, reflecting fetal asphyxia. Presumably these findings indicate that if umbilical flow falls and uterine flow is maintained there is better equilibration of blood gases in fetal blood with maternal blood. This relation is similar to the ventilation-perfusion relation in the postnatal lung.

The observation that there is an increase in the proportion of the cardiac output distributed to the placenta with advancing gestational age is open to some question. This could be a valid observation, but it could be related to the fact that the very small vessels in the umbilical cord in the younger fetuses are more easily and more rapidly obstructed. The finding that there is a statistically significant relation between fetal arterial $\mathrm{pH}$ and the proportion of cardiac output to the placenta (Fig. 7 a) suggests that when placental flow is lower it is inadequate for maintaining adequate fetal oxygenation. The low placental flow also explains why the inferior vena caval contribution to cardiac output, relative to superior vena caval contribution, is reduced in the smaller fetuses. An interference with umbilical circulation, with an increase in umbilicoplacental vascular resistance, would also explain the findings of a larger proportion of inferior vena caval blood and of total cardiac output distributed to the upper body in the younger fetuses (Fig. $2 a, b$ ). The $\mathrm{pH}, \mathrm{PCO}_{2}$, and $\mathrm{PO}_{2}$ changes associated with progressive deterioration of the umbilical circulation allowed us to determine the effects of blood gas variation on distribution of cardiac output to various organs. It was evident that in the human fetus of early gestational age, there is a redistribution of cardiac output associated with asphyxia, similar to that observed in the lamb at a relatively later period of gestation [6]. There was a significant increase in the proportion of cardiac output supplied to the myocardium and to the brain as fetal arterial $\mathrm{pH}$ fell, and there was a striking relation between increase of cerebral blood flow and increase in arterial $\mathrm{PCO}_{2}$. These observations are in agreement with the findings of Barker in fetal rabbits [1] and of Campbell et al. [2] and Purves and James [11]. It was also most interesting that a reduction in arterial $\mathrm{pH}$ was associated with an increase in adrenal blood flow.

The cardiac output measurements were quite variable, and the mean value was somewhat lower than that of the fetal lamb in utero [13]. This is probably related to delivery of the fetus but could also be a result of the anesthesia. The values are, however in the same range as those observed in exteriorized fetal lambs by Mahon et al. [8]. The proportionate distribution of 
cardiac output to the fetal organs was similar to that seen in the lamb [13] except that a much greater percentage (mean 14\%) was received by the brain; about $3 \%$ was observed in the brains of fetal lambs.

The fetal arterial pressures demonstrated an increase in mean levels with increasing fetal weight. In the two larger fetuses, whose gestational ages were about 20 weeks, the mean pressure of $35 \mathrm{~mm} \mathrm{Hg}$ was similar to that in the lamb halfway through gestation [3].

The marked difference in the proportion of umbilical venous return which passed through the ductus venosus in different fetuses is unexplained. It was not related to the total umbilical blood flow since in individual fetuses in which two or three observations were made there was relatively little change in the proportion of umbilical venous flow through the ductus venosus despite marked changes in the proportion of cardiac output distributed to the placenta. It was also unrelated to variations in blood gases or fetal weight. It is possible that the differences between fetuses could be related to differences in hepatic vascular resistance or some variation in the anatomical arrangement of the umbilical vein as it enters the portal venous system.

\section{Appendix}

The following assumptions and exclusions were made in the calculation of cardiac output and its distribution:

(1) Only a small proportion of superior vena caval return crosses the foramen ovale, and, therefore, most of the blood supply to the upper body, brain, and heart is derived from inferior vena caval return.

(2) Although pulmonary venous return does contribute to cardiac output, it is a relatively small proportion of total venous return and has, therefore, been excluded.

(3) Azygous venous return, which drains a small portion of the lower body, has also been excluded from the calculations.

\section{Terms Used}

$\mathrm{CO}$

$\dot{\mathrm{Q}}$

IVC

SVC

$\mathrm{H}$

I
Total

Total counts per minute injected into the IVC, i.e., in an umbilical venous injection the absolute total injected less the amount in the liver, in other words, the amount bypassing the liver through the ductus venosus and thereby reaching the IVC

Upper organ Organ deriving its blood flow from the aorta before it is joined by the ductus arteriosus

UBB Upper body and brain

Lower organ Organ deriving its blood flow from the aorta after entry of the ductus arteriosus

Total LB Total lower body, viz., lower body, trunk CA and legs, abdominal viscera, and placenta Carotid artery

$$
\begin{aligned}
\mathrm{CO}= & \dot{\mathrm{Q} I V G}+\dot{\mathrm{Q} S V C}+\dot{\mathrm{Q}} \mathrm{H} \\
= & \dot{\mathrm{Q}} \mathrm{IVC}+\dot{\mathrm{Q} I V C}\left(\frac{\mathrm{I} \text { UBB }}{\mathrm{I} \text { TOTAL }}\right) \\
& +\dot{\mathrm{Q} I V C}\left(\frac{\mathrm{I} H}{\mathrm{I} \text { TOTAL }}\right)
\end{aligned}
$$

\section{For upper organs}

The proportion of CO to each upper organ, viz., upper body, brain and heart

$$
\begin{aligned}
& =\frac{\dot{\mathrm{Q}} \text { UPPER ORGAN }}{\text { CO }} \\
& =\frac{\dot{\text { IVC }\left(\frac{\text { I UPPER ORGAN }}{\text { I TOTAL }}\right)}}{\text { CO }}
\end{aligned}
$$

From equation 2

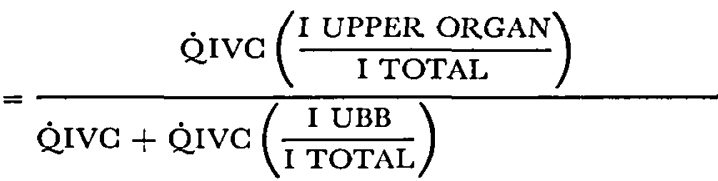

$$
\begin{aligned}
& +\dot{Q} I V C\left(\frac{\text { I H }}{\text { I TOTAL }}\right)
\end{aligned}
$$

$$
\begin{aligned}
& =\frac{\text { QIVC }\left(\frac{\text { I UPPER ORGAN }}{\text { I TOTAL }}\right)}{\text { Q'IVC }\left(1+\frac{\text { I UBB }}{\text { I TOTAL }}+\frac{\text { I H }}{\text { I TOTAL }}\right)} \\
& =\frac{\frac{\text { I UPPER ORGAN }}{\text { I TOTAL }}}{1+\frac{\text { I UBB }}{\text { I TOTAL }}+\frac{\text { I H }}{\text { I TOTAL }}}
\end{aligned}
$$




$$
=\left(\frac{\text { I UPPER ORGAN }}{\text { I TOTAL }}\right) \frac{1}{1+\frac{\text { I UBB }}{\text { I TOTAL }}+\frac{\text { I H }}{\text { I TOTAL }}}
$$

where

$$
\frac{1}{1+\frac{\text { I UBB }}{\text { I TOT } A L}+\frac{\text { I H }}{\text { I TOTAL }}}
$$

is a constant $k$ for each fetus.

\section{Similarly for lower organs}

the proportion of $\mathrm{CO}$ to each lower body organ, viz., kidneys, gut, placenta, etc.

$$
\begin{aligned}
& =\frac{\dot{Q} \text { LOWER ORGAN }}{\text { CO }} \\
& =\frac{\dot{\operatorname{IVV}}\left(\frac{\text { I LOWER ORGAN }}{\text { I TOTAL LB }}\right)}{\text { CO }}
\end{aligned}
$$

and as in the derivation of equation 8 from equation 4

$$
\begin{gathered}
=\left(\frac{\text { I LOWER ORG } A N}{\text { I TOTAL LB }}\right) \\
\frac{1+\frac{\text { I UBB }}{\text { I TOTAL }}+\frac{\text { I H }}{\text { I TOTAL }}}{1}
\end{gathered}
$$

where

$$
\frac{1}{1+\frac{\text { I UBB }}{I \text { TOTAL }}+\frac{\text { I H }}{\text { I TOTAL }}}
$$

is the same constant as constant $k$ derived in equation 8 .

To calculate actual organ flow using carotid artery sample:

\section{Upper organ flow}

$\frac{\dot{Q} \text { UPPER ORGAN }}{\dot{Q} \text { CA SAMPLE }}=\frac{\text { I UPPER ORGAN }}{\text { I GA SAMPLE }}$

$\dot{Q}$ UPPER ORGAN $=\dot{Q}$ CA SAMPLE

$$
\text { ( }\left(\frac{\text { I UPPER ORGAN }}{\text { I CA SAMPLE }}\right)
$$

Lower organ flow

$$
\begin{aligned}
\frac{\dot{\mathrm{QSVC}}+\dot{\mathrm{Q}} \mathrm{H}}{\dot{\mathrm{Q} I V C}} & =\frac{\mathrm{I} \mathrm{UBB}+\mathrm{I} \mathrm{H}}{\mathrm{I} \text { TOTAL }} \\
\dot{\mathrm{Q} I V G} & =\left(\frac{\dot{\mathrm{Q} S V C}+\dot{\mathrm{Q} H}}{\mathrm{I} \mathrm{UBB}+\mathrm{I} H}\right) \text { I TOTAL }
\end{aligned}
$$

Since $\dot{Q} S V C$ and $\dot{Q} H$ can be calculated from equation 13, QIVC is known; then to calculate individual lower organ flow.

$$
\begin{aligned}
& \frac{\dot{Q} \text { LOWER ORGAN }}{\dot{Q} \text { IVG }}=\frac{\text { I LOWER ORGAN }}{\text { I TOTAL LB }} \\
& \dot{Q} \text { LOWER ORGAN }=\left(\frac{\text { I LOWER ORGAN }}{\text { I TOTAL LB }}\right) \dot{\text { IVC }}
\end{aligned}
$$

\section{References and Notes}

1. BARKER, J. N.: Fetal and neonatal cerebral blood flow. Amer. J. Physiol., 210: 897 (1966).

2. Campbell, A. G. M., Dawes, G. S., Fishman, A. P., and HyMAN, A. I.: Regional redistribution of blood flow in the ma. ture fetal lamb. Circ. Res., 21: 229 (1967).

3. Dawes, G. S.: Foctal and Neonatal Physiology, p. 97 (Year Book Medical Publishers, Chicago, 1968).

4. Domenech, R. J., Hoffman, J. I. E., Noble, M. I. M., SAunders, K. B., Henson, J. R., and Subijanto, S.: Total and regional coronary blood flow measured by radioactive microspheres in conscious and anesthetized dogs. Circ. Res., 25: 581 (1969).

5. Heymann, M. A., and Rudolpi, A. M.: Effect of exteriorization of the sheep fetus on its cardiovascular function. Circ. Res., 21: 741 (1967).

6. Kitterman, J. A., Rudolpi, A. M., and Heyaiann, M. A.: Unpublished observations.

7. Lind, J., and Wegelius, C.: Human fetal circulation. Cold Spring Harbor Symp. Quant. Biol., 19: 109 (1954).

8. Mahon, W. A., Goodwin, J. W., and Paul, W. M.: Measurement of individual ventricular outputs in the fetal lamb by a dye dilution technique. Circ. Res., 19: 191 (1966).

9. Makowski, E. L., Meschis, G., Droegmueller, W., ANd Battaglia, F. C.: Measurement of umbilical arterial blood flow to the shcep placenta and fetus in utero. Circ. Res., 23: 623 (1968).

10. Peltonen, T., and Hirvonen, L.: Experimental studies on fetal and neonatal circulation. Acta Paediat. Suppl., 161 (1965).

11. Purves, M. J., and James, I. M.: Observations on the control of cerebral blood flow in the sheep fetus and newborn lamb. Circ. Res., 25: 651 (1969).

12. Rudolih, A. M., And Heymann, M. A.: Circulation of the fetus in utcro. Circ. Res., 21: 163 (1967).

13. Rudolph, A. M., and Heyman,, M. A.: Circulatory changes during growth in the fetal lamb. Circ. Res., 26: 289 (1970).

14. Nuclear Products Division, 3 M Company, St. Paul, Minn.

15. Mamn Research Laboratories, Division of B-D Laboratories, New York, N. Y.

16. Hewlett-Packard Company, Palo Alto, Calif.

17. Radiometer A/S, Copenhagen, Denmark.

18. Nuclear-Chicago, Division of G. D. Searle, Des Plaines, IIl.

19. 404C, Technical Instruments, North Haven, Conn.

20. 535, Technical Instruments.

21. Model 379-19B, Wang Laboratories, Tewksbury, Mass.

22. Model 380, Wang Laboratories.

23. We would like to express our appreciation to Professor Paavo Vara and Sakari Timonen for providing the facilities and opportunity to perform these studies. We also acknowledge 
the assistance and cooperation of the Obstetric staff, the Anesthesiology staff, and the Nursing personnel at the Women's Clinic of the Helsinki University Central Hospital.

24. Supported by National Heart and Lung Institute Program Projects Grant no. HE-06285 and by the Association for the Aid of Crippled Children, New York. Dr. Hcymann is the recipient of Public Health Service Research Career Development Award no. HD 35398 from the National Institute of
Child Health and Human Development. Dr. Barrett was supported by Public Health Service Special Research Fellowship no. HD 39496 from the National Institute of Child Health and Human Development.

25. Requests for reprints should be addressed to: Abraham M. Rudolph, M.D., Room 1403 HSE, University of California, San Francisco, San Francisco, Calif. 94122 (USA).

26. Accepted for publication November 5, 1970. 